\title{
Mechanical and Tribological Characteristics of Aluminium 2618 Matrix Composite Reinforced with Boron Carbide
}

\author{
Sharath Peramenahalli Chikkegouda ${ }^{1}$, Gurudath $B^{1}$, Sharath B ${ }^{2}$ (D), Karthik $S^{2}$, Rayappa \\ Shrinivas Mahale ${ }^{3, * \text { (D) }}$
}

1 Department of Metallurgical and Materials Engineering, JAIN Deemed to be University, Bengaluru, Karnataka, India; pcsharath1988@gmail.com (S.P.C.), grdth1@gmail.com (G.B.);

2 Department of Mechanical Engineering, Malnad College of Engineering, Hassan, Karnataka, India; sharathbn04@gmail.com (S.B.N.), mechkarth@gmail.com (K.S.);

3 School of Mechanical Engineering, REVA University, Bengaluru, Karnataka, India; rayappamahale@gmail.com (R.S.M.);

* Correspondence: rayappamahale@gmail.com (R.S.M.);

Scopus Author ID 57220036422

Received: 15.08.2021; Revised: 20.09.2021; Accepted: 23.09.2021; Published: 3.10.2021

\begin{abstract}
Aluminium-based alloys are mainly used for bearing and automotive applications, resulting in more wear and tear of the material. Boron Carbide $\left(\mathrm{B}_{4} \mathrm{C}\right)$, hard ceramic materials used as reinforcement in Al2618 matrix material, was fabricated using the stir casting method. The presence and distribution of the $\mathrm{B}_{4} \mathrm{C}$ particles were confirmed by X-ray diffractometer (XRD) and Scanning Electron Microscopy (SEM). Taguchi's design of experimental approach was employed to study the wear characteristics using the L27 orthogonal array. Optimization of parameters like applied load (20, 30 , and $40 \mathrm{~N})$, sliding distance $(400,600$, and $800 \mathrm{~m})$, and sliding speed $(1.25,2.51$, and $3.76 \mathrm{~m} / \mathrm{s})$ were done using Signal-to-Noise ratio analysis and Analysis of Variance (ANOVA). Results revealed that speed $(46.77 \%)$ had more influence on wear behavior, followed by sliding distance $(34.74 \%)$ and load (9.81\%). SEM images of the worn-out composite specimens exhibited an adhesive type of wear mechanism with deep grooves from hard $\mathrm{B}_{4} \mathrm{C}$ particles.
\end{abstract}

Keywords: Al alloy; aging heat treatment; taguchi technique; ANOVA; scanning electron microscope; wear.

(C) 2021 by the authors. This article is an open-access article distributed under the terms and conditions of the Creative Commons Attribution (CC BY) license (https://creativecommons.org/licenses/by/4.0/).

\section{Introduction}

Due to the drastic advancement in material technology, selecting the materials suitable for specific applications according to requirements is necessary. Due to the low density, high thermal conductivity, high specific strength, and resistance against corrosion, Aluminium ( $\mathrm{Al}$ ) and its alloys are ideal for structural applications, and these alloys are commonly used in the aerospace and lightweight car industries because of their considerable weight reduction and fuel economy, which is an additional economic advantage [1]. However, in high-performance tribological applications, $\mathrm{Al}$ alloys fall short due to low hardness and wear resistance. In recent decades, there have been many substantial interests from intensive studies concentrating on strong ceramic particles, whiskers, and fiber-reinforced aluminum metal matrix composites (AMMs). Conventional aluminum alloys have restrictions on performance, hardness, durability, wear resistance, fatigue, and working conditions with high temperatures [2]. The optimum MMC characteristics and increased material efficiency must require excellent 
reinforcement and processing techniques. Al alloys are extensively used in IC engines, hydraulic gear pumps, reciprocating compressors, and aircraft machinery [3, 4]. Owing to its low density, better serviceable bearing parts can be produced. Relative motion between the mated mechanical components will tend to wear, thus compromising the assembly's structural integrity. Efforts have been made to understand the wear mechanism to mitigate the wear rate of machine elements by replacing conventional Al alloys with AMM's for better wear-resistant and service life of the components [5]. Earlier research focused on implementing low-density ceramic materials into low-density materials such as Al and magnesium [6]. Many researchers have studied the effect of reinforcement on wear behavior; few such studies are highlighted here. Suresha et al. [7] investigated the effect of $\mathrm{SiC}$ and $\mathrm{Gr}$ on the $\mathrm{Al}$ matrix. They concluded that wear resistance improved in hybrid mixture due to uniform mixture of $\mathrm{Gr}$ and $\mathrm{SiC}$ enhancing the bonding strength between base alloys. However, the wear rate decreased as speed, load and distance increased. Similar studies were carried out by Basavarajappa et al. [8] and concluded that as the speed increases, the degree of subsurface deformation also increases. The graphite-free composite exhibits much subsurface deformation in comparison to hybrid composite. AA 6061 matrix and titanium carbide has reinforcement used by Gopalakrishnan and Murugan [9] to study the wear characteristics and found out that specific strength of AlTiC composite had increased as the TiC addition increased in percentage and wear loss increased linearly with applied load. V Kumar et al. [10] explored wear behavior on the SiC reinforced Al6061 composite fabricated via the liquid metallurgy route. It showed particulate reinforced metal matrix composites exhibited improved wear resistance. The particulate reinforced composite demonstrated excellent processing capability over fiber/whiskers-based composites. The wear behavior of age-hardened Al 6061 alloy was studied by Gowrishankar et al. [11]. Results showed improved wear resistance for age-hardened alloy as compared to solutionized alloy. Sanjib Banerjee et al. [12] studied the influence on 2219 alloy by variable tin (sn) content of rolling and aged heat treatment. They showed that the impact strength and ductility were decreased up to $0.06 \mathrm{wt} \%$ in rolled composites, and after aging, impact strength and tensile strength increased by 0.06 wt. \% Sn and decreased with further additions of Sn. Mahagundappa et al. [13] studied the aging and wore properties of hybridized Al6061- $9 \%$ SiC \& $0,1,3$, and $5 \%$ of E-glass fiber. The result showed a positive correlation between wear resistance and aging time ranging from 1, 3, 5, and 7 hours. From the above studies, it is clear that the addition of ceramic particulate reinforcement improves the tribological properties with lesser addition of reinforcement. Little detail is rendered about A12618's wear properties as a reinforcing particle with a high proportion of $\mathrm{B}_{4} \mathrm{C}$. In the present study, dry sliding wears resistance of the $\mathrm{Al} 2618$ matrix with $10 \mathrm{wt}$. $\%$ of $\mathrm{B}_{4} \mathrm{C}$ addition were evaluated using a design of experimental approach. The age hardening process was carried out on the composites as a secondary process to improve the tribological properties.

\section{Materials and Methods}

\subsection{Material.}

Al2618 alloy as the matrix and Boron Carbide $\left(\mathrm{B}_{4} \mathrm{C}\right)$ used as reinforcement (10 wt. \%). The matrix material is $\mathrm{Al}-\mathrm{Cu}-\mathrm{Mg}$ alloy, and its nominal alloying composition is given in Table 1. The addition of Boron carbide as reinforcement in $\mathrm{Al} 2618$ was fabricated by using a stir casting route. Al2618 alloy melted around $1 \mathrm{~kg}$ at $700^{\circ} \mathrm{C}$. Nitrogen was used for degassing the melt. To ensure proper mixing, a zirconium-coated stainless steel stirrer with four blades was 
used to prevent ferrous material diffusion into the matrix material during stirring. The stirring speed was kept constant at $600 \mathrm{rpm}$ for 15-20 min, and the mechanical stirrer's immersion was held to about two-thirds of the depth of the molten metal [14]. Before applying the reinforcement to the melt, it was preheated to $600{ }^{\circ} \mathrm{C}$. During stirring, the preheated particles $(40-50 \mu \mathrm{m})$ were added to the molten slurry and poured into the die. Solution heat treatment was carried out at $540{ }^{\circ} \mathrm{C}$ for $120 \mathrm{~min}$ and was water quenched. Subsequent aging was carried out at $200{ }^{\circ} \mathrm{C}$ for $240 \mathrm{~min}$ [15]. The aging temperature was restricted to $200{ }^{\circ} \mathrm{C}$. Beyond this temperature, aging is not favorable due to the effect of recrystallization [16].

\begin{tabular}{l|c|c|c|c|c|c|c|c|c|c|c|c} 
Table 1. Elemental composition of A1 2618 alloy. \\
Element & $\mathbf{S i}$ & $\mathbf{F e}$ & $\mathbf{C u}$ & $\mathbf{M n}$ & $\mathbf{M g}$ & $\mathbf{C r}$ & $\mathbf{N i}$ & $\mathbf{Z n}$ & $\mathbf{T i}$ & $\mathbf{B}$ & $\mathbf{C a}$ & $\mathbf{A l}$ \\
\hline Wt. \% & 0.24 & 1.30 & 2.52 & 0.004 & 1.46 & 0.02 & 1.14 & 0.01 & 0.07 & 0.003 & 0.002 & Balance
\end{tabular}

\subsection{Wear analysis.}

Samples were machined according to ASTM G99-95 (10 mm diameter x $30 \mathrm{~mm}$ length) standards. Pin-on-Disc was used to carry out a wear test at room temperature, as shown in Figures 1 (a) and (b). The disc is made of EN-32 steel with a track diameter of $120 \mathrm{~mm} \&$ thickness $8 \mathrm{~mm}$. All the test specimens were ground using a series of abrasive (800-1000 grade) papers. Before conducting the wear test, the samples were weighed with an accuracy of $0.0001 \mathrm{~g}$ using an electronic weighing scale. Acetone was used to clean the disc's surface and the samples to remove oil, grease, and other debris before and after performing the test. Brinell hardness measurements were carried out on samples according to ASTM B647-10. An average of six readings was recorded. Wear test conditions are illustrated in Table 2. By applying the weight-loss method, the sample's weight loss was determined as an average of three runs. The wear rate was calculated with the formula [17].

Wear rate $=$ Average weight loss $/($ density $*$ sliding distance $)$

Table 2. Control factors and their levels.

\begin{tabular}{l|c|c|c} 
& \multicolumn{3}{|c}{ Levels } \\
\hline Control factors & 1 & 2 & 3 \\
\hline Load in N & 20 & 30 & 40 \\
\hline Speed in $\mathrm{m} / \mathrm{s}$ & 1.25 & 2.51 & 3.76 \\
\hline Sliding distance in $\mathrm{m}$ & 400 & 600 & 800
\end{tabular}

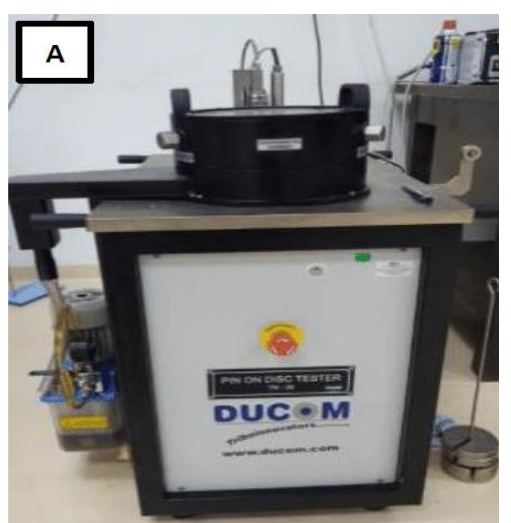

(A)

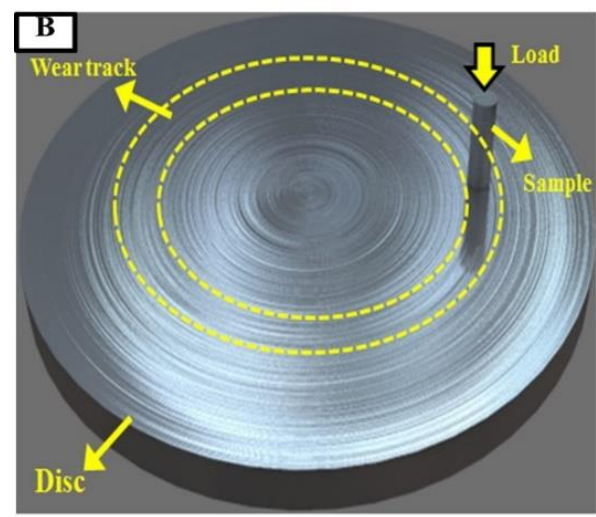

(B)

Figure 1. (A) Pin-on-Disc setup; (B) Schematic view of Pin-on-Disc wear test. 


\subsection{Statistical analysis.}

The influences of control factors and their interactions on the tribological behavior were also studied using the Taguchi method. This method involves transforming the experimental results to a signal-to-noise $(\mathrm{S} / \mathrm{N})$ ratio, and lower-the-better criteria were adopted. To corroborate for statistical significance of the interacting parameters, analysis of variance was performed, and the best possible combinations were predicted.

\section{Results and Discussion}

\subsection{Microstructure and XRD analysis.}

The microstructure of $\mathrm{B}_{4} \mathrm{C}$ reinforced with $\mathrm{Al} 2618$, and the heat-treated alloy is shown in above Figure 2 (a) and (b). It is observed from Figure 2(a) that the grey region represents the $\mathrm{Al}$ matrix, and the white region represents the presence of the $\mathrm{B}_{4} \mathrm{C}$ particles. The $\mathrm{B}_{4} \mathrm{C}$ particles are segregated along the grain boundary, as seen in Figure 2(a). It also reveals good interfacial bonding between $\mathrm{A} 12618$ and $\mathrm{B}_{4} \mathrm{C}$ particles. Figure 2(b) shows that alloy's precipitation-hardened grain size decreases than the $\mathrm{Al} 2618+10 \% \mathrm{~B}_{4} \mathrm{C}$ composites. The composite's average Brinell hardness (BHN) was $109 \mathrm{~kg} / \mathrm{mm}^{2}$, and after age-hardening, the hardness increased to $129 \mathrm{~kg} / \mathrm{mm}^{2}$. It shows that a fine grain strengthening mechanism improves the hardness of the alloy. X-ray diffraction (XRD) pattern indicates the presence of $\mathrm{Al}$ and $\mathrm{B}_{4} \mathrm{C}$ and the minute amount of copper and magnesium, as shown in Figure 3.
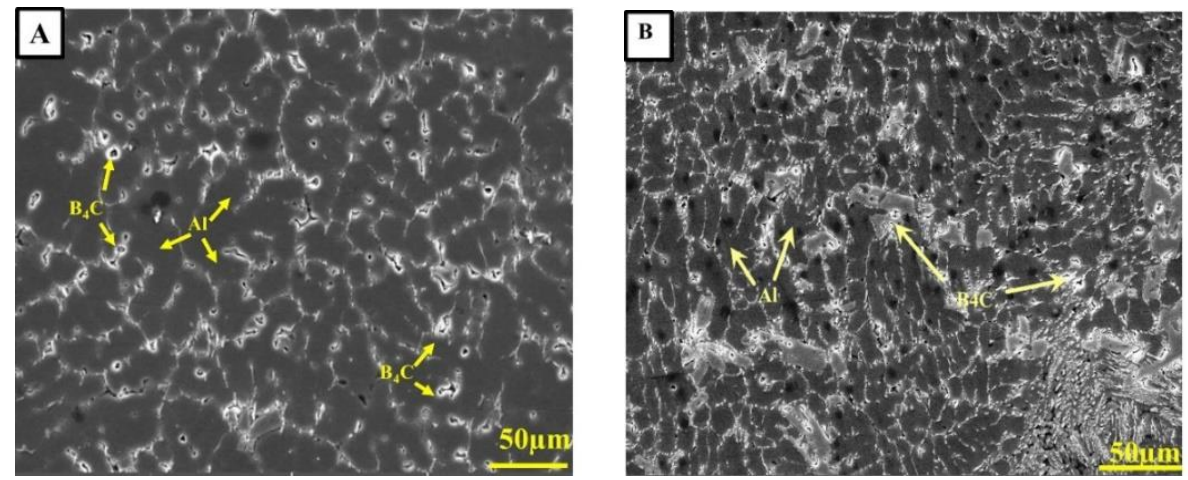

Figure 2. SEM of the $\mathrm{Al} 2168$ matrix composites with (A) $10 \% \mathrm{~B}_{4} \mathrm{C}$; (B) 10 wt. $\% \mathrm{~B}_{4} \mathrm{C}+$ heat treated.

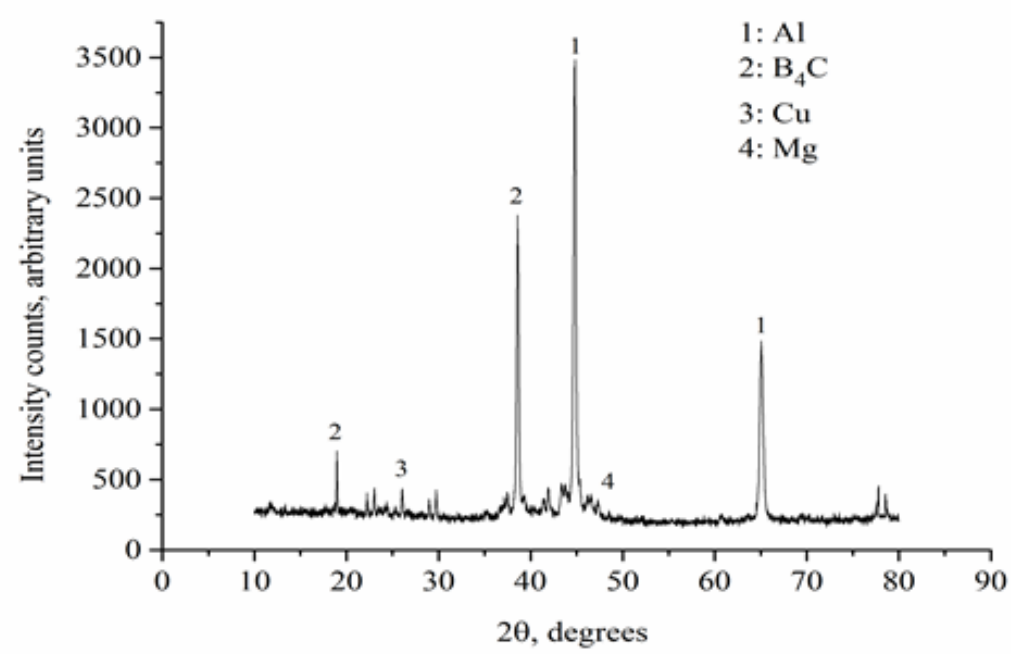

Figure 3. $\mathrm{XRD}$ pattern showing the presence of reinforcement $\mathrm{B}_{4} \mathrm{C}$ particles. 


\subsection{Evaluation of wear behavior.}

3.2.1. Analysis of factors.

$\mathrm{S} / \mathrm{N}$ ratios for the experimental trials are shown in Table 3. These ratios were calculated using the statistical software tool Minitab15 to evaluate the factors influencing wear rate. The delta values for specific factors were derived from $\mathrm{S} / \mathrm{N}$ ratios, as shown in Table 4 . The degree of affecting factors was ranked from highest to lowest. The highest is the sliding speed, followed by distance and load being the lowest. The Al composites wear rate increases with an increase in the load and the sliding velocity but decreases with distance $[18,19]$. The highest wear rate value of $1.679 \mathrm{~mm}^{3} / \mathrm{m}$ was obtained for $40 \mathrm{~N}, 3.76 \mathrm{~m} / \mathrm{s}$, and $400 \mathrm{~m}$ and the lowest value of $0.419 \mathrm{~mm} 3 / \mathrm{m}$ for $20 \mathrm{~N}, 1.25 \mathrm{~m} / \mathrm{s}$, and $800 \mathrm{~m} \mathrm{[20].} \mathrm{In} \mathrm{this} \mathrm{study,} \mathrm{sliding} \mathrm{speed} \mathrm{has} \mathrm{a}$ more significant effect on wear rate due to the oxidative wear at the speed of $3.76 \mathrm{~m} / \mathrm{s}$. This type of behavior was observed by Sahin and Murphy [21]. Figures 4 (A) and (B) demonstrate the main effect and interaction plots for the wear rate of the Al2618 and reinforced Al2618. Higher the $\mathrm{S} / \mathrm{N}$ ratio, the lower the variety of particular wear rates across the desired value. The response graphs made it very simple to decide the optimal testing conditions for these control variables. The graphs depict the transition in the $\mathrm{S} / \mathrm{N}$ ratio as the control factor setting was shifted from one stage to the next. The graphs with the highest $\mathrm{S} / \mathrm{N}$ values had the best specific wear rate. In Figure 4A, the initial optimum state for the test samples is $40 \mathrm{~N}, 3.76 \mathrm{~m} / \mathrm{s}$, and $800 \mathrm{~m}$ for key control factors sliding speed. Like previous research on aluminum composite materials, wear rate decreased as the magnitude of applied load and sliding speed increased $[22,23]$. The interaction plots outline the effects of variables on wear rate, as shown in Figure 5. One of the features was kept constant for any given plot, and the effects of the other two remaining features (horizontal axis and legends) were plotted against the wear rate. For instance, the first row first column shows a plot for sliding speed versus wear rate at a constant distance of 400m for different load values, as shown in the legend. The effect of normal load on wear rates was highly pronounced, with wear rate increasing steeply as the load's magnitude increased. This is a normal occurrence in most of the material. Furthermore, as the load and the friction at the pin-disc interface increased, the scale of the wear debris became larger. Consequently, the propensities of wear failure occur at higher loads. The effect of sliding speed on wear rate was most severe. As the material is exposed to sliding wear, it undergoes rapid plastic deformation at the surface and sub surfaces. Increased wear rate was observed at higher sliding speeds because of increased temperature and matrix thermal softening. Sliding distance had the least impact on wear rate, with wear rate declining as the sliding distance increased. This may be attributed to the mechanism of strain hardening.

Table 3. Experimental results for wear rate with calculated $\mathrm{S} / \mathrm{N}$ ratio.

\begin{tabular}{c|c|c|c|c|c|c} 
Sr. No & Load in N & Speed in $\mathbf{~} / \mathbf{s}$ & Distance in $\mathbf{~}$ & Weight loss in $\mathbf{~ m - g m}$ & Wear $\mathbf{~ r a t e ~} \mathbf{~ m m}^{\mathbf{3} / \mathbf{m}}$ & S/N ratio \\
\hline 1 & 20 & 1.25 & 400 & 0.0012 & 0.559 & 4.89225 \\
\hline 2 & 20 & 1.25 & 600 & 0.0014 & 0.4353 & 4.9064 \\
\hline 3 & 20 & 1.25 & 800 & 0.0018 & 0.419 & 4.49901 \\
\hline 4 & 20 & 2.51 & 400 & 0.0022 & 1.026 & 2.68278 \\
\hline 5 & 20 & 2.51 & 600 & 0.0026 & 0.808 & 2.27539 \\
\hline 6 & 20 & 2.51 & 800 & 0.0029 & 0.676 & 2.66863 \\
\hline 7 & 20 & 3.76 & 400 & 0.0032 & 1.492 & -0.34004 \\
\hline 8 & 20 & 3.76 & 600 & 0.0035 & 1.088 & 0.0532 \\
\hline 9 & 20 & 3.76 & 800 & 0.0038 & 0.886 & 0.06735 \\
\hline 10 & 30 & 1.25 & 400 & 0.0021 & 0.979 & 3.04598 \\
\hline 11 & 30 & 1.25 & 600 & 0.0025 & 0.777 & 3.06014 \\
\hline 12 & 30 & 1.25 & 800 & 0.0029 & 0.676 & 2.65274
\end{tabular}




\begin{tabular}{c|c|c|c|c|c|c} 
Sr. No & Load in N & Speed in $\mathbf{~} / \mathbf{s}$ & Distance in $\mathbf{~}$ & Weight loss in $\mathbf{~ m - g m}$ & Wear rate $\mathbf{~ m m} \mathbf{3} / \mathbf{m}$ & S/N ratio \\
\hline 13 & 30 & 2.51 & 400 & 0.0024 & 1.119 & 0.83651 \\
\hline 14 & 30 & 2.51 & 600 & 0.0027 & 0.839 & 0.42912 \\
\hline 15 & 30 & 2.51 & 800 & 0.003 & 0.699 & 0.82236 \\
\hline 16 & 30 & 3.76 & 400 & 0.0033 & 1.539 & -2.18631 \\
\hline 17 & 30 & 3.76 & 600 & 0.0037 & 1.15 & -1.79307 \\
\hline 18 & 30 & 3.76 & 800 & 0.004 & 0.932 & -1.77892 \\
\hline 19 & 40 & 1.25 & 400 & 0.0023 & 1.072 & 2.32086 \\
\hline 20 & 40 & 1.25 & 600 & 0.0027 & 0.839 & 2.33501 \\
\hline 21 & 40 & 1.25 & 800 & 0.003 & 0.699 & 1.92762 \\
\hline 22 & 40 & 2.51 & 400 & 0.0026 & 1.212 & 0.11139 \\
\hline 23 & 40 & 2.51 & 600 & 0.0031 & 0.963 & -0.29601 \\
\hline 24 & 40 & 2.51 & 800 & 0.0033 & 0.769 & 0.09723 \\
\hline 25 & 40 & 3.76 & 400 & 0.0036 & 1.679 & -2.91144 \\
\hline 26 & 40 & 3.76 & 600 & 0.004 & 1.243 & -2.5182 \\
\hline 27 & 40 & 3.76 & 800 & 0.0043 & 1.002 & -2.50404
\end{tabular}

Table 4. Response table for $\mathrm{S} / \mathrm{N}$ ratios (smaller is better).

\begin{tabular}{c|c|c|c} 
Level & Load & Speed & Sliding distance \\
\hline 1 & 2.4117 & 3.2933 & -1.1065 \\
\hline 2 & 0.5654 & 1.0697 & 1.2010 \\
\hline 3 & -0.1597 & -1.5457 & 2.7229 \\
\hline Delta & 2.5714 & 4.8391 & 3.8294 \\
\hline Rank & 3 & 1 & 2
\end{tabular}

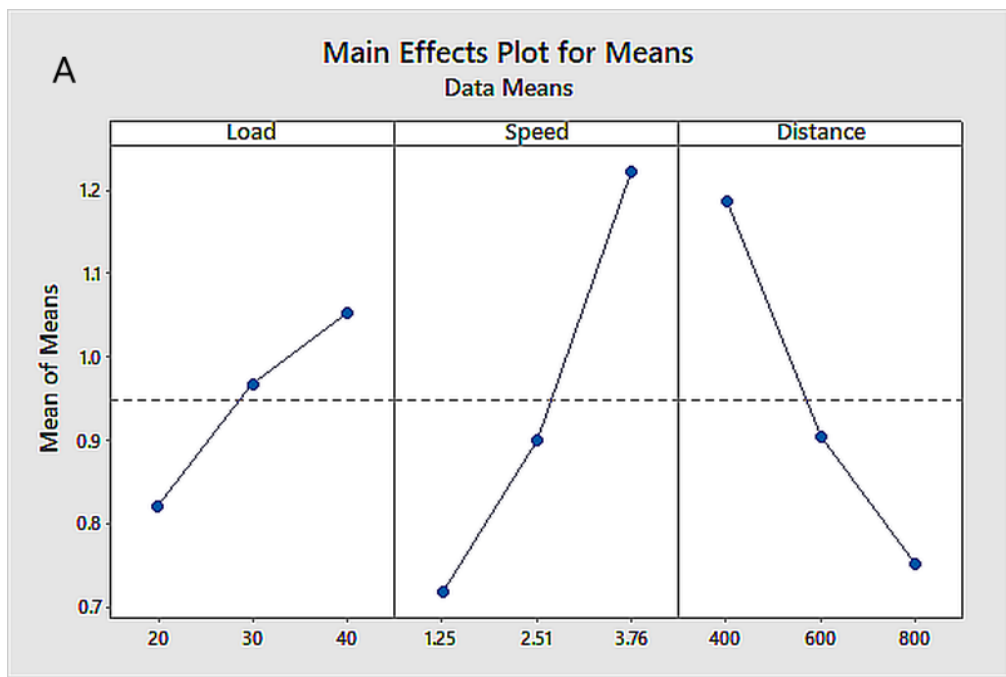

Figure 4. Main effect plots for specific wear rate of $\mathrm{Al}$ composites (A) S/N ratio.

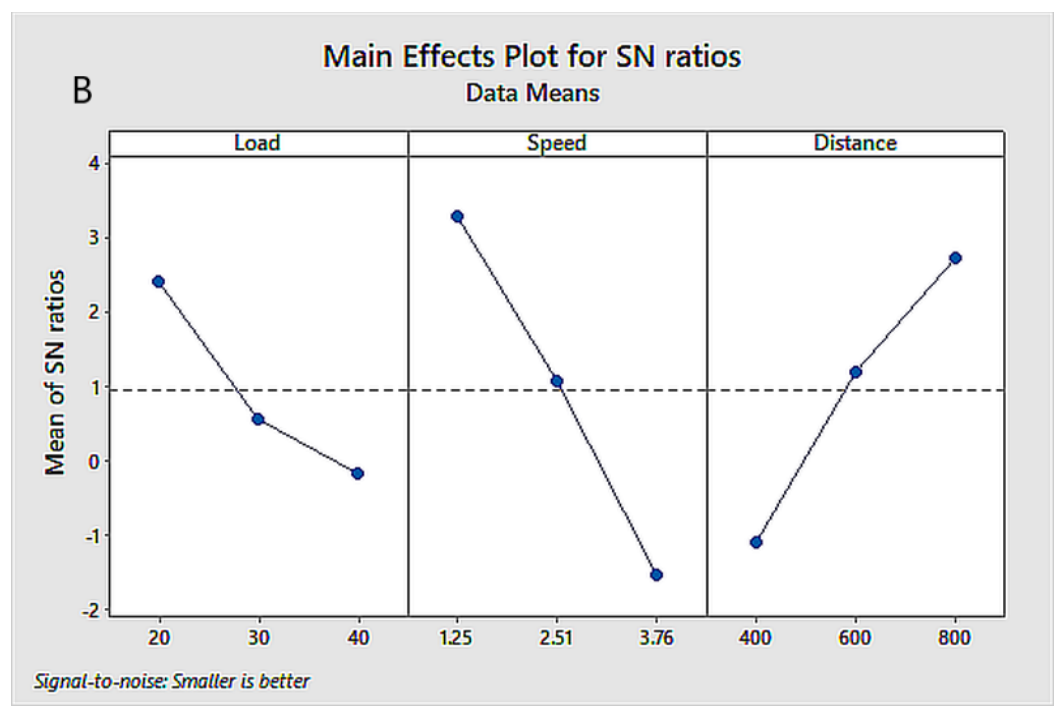

Figure 4. Main effect plots for specific wear rate of Al composites (B) Mean. 


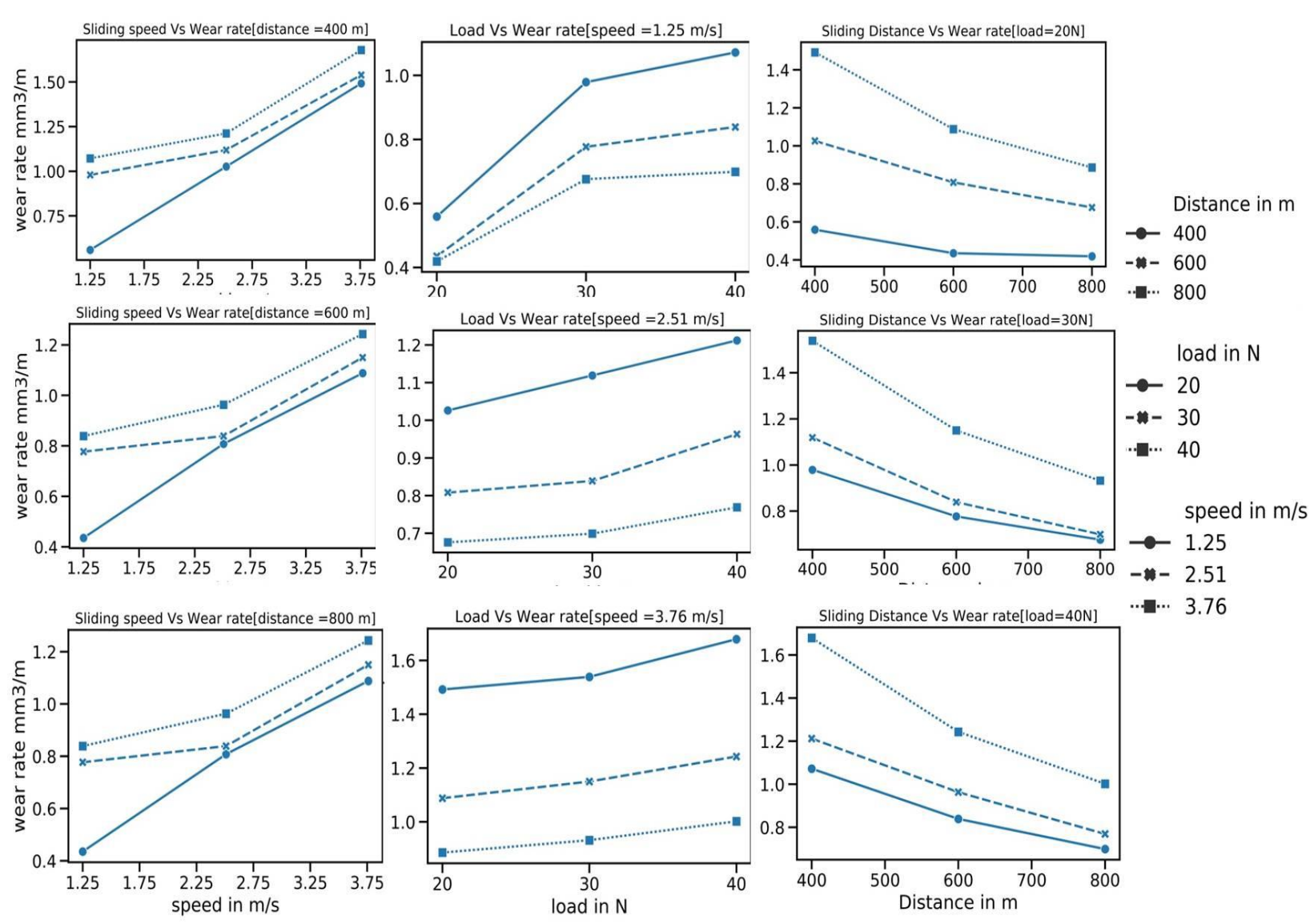

Figure 5. Interaction factor effect plots for wear rate.

\subsubsection{ANOVA analysis.}

The analysis of variance (ANOVA) was used to look at the architecture criteria that directly impacted the output characteristics. It was achieved by calculating the cumulative uncertainty of the S/N ratio, calculated as the sum of the square deviations from the total mean $\mathrm{S} / \mathrm{N}$ ratio. Table 5 shows the percentage contribution of each parameter chosen individually. It shows the means analysis outcome. The degrees of freedom (DF), the sum of squares (SS), mean squares (MS), F significance, and percentage contribution (P \%) of each factor on the total variance are all explained in the ANOVA Table 5. According to Table 5, the percentage contribution of sliding speed is highest $(46.77 \%)$ followed by sliding distance $(34.74 \%)$ and the least contribution being the applied load $(9.81 \%)$ which is of less significance in the present work. As shown in Figure 6, speed and weight loss are positively correlated to wear rate from the correlation plot. The parameter speed has the highest positive correlation, and the parameter distance has the highest negative correlation. These data suggest that sliding speed and distance have a high significance level and are following the ANOVA for means.

Table 5. ANOVA for reinforced composite.

\begin{tabular}{l|c|c|c|c|c|c|c} 
Source & $\mathbf{D F}^{\mathbf{a}}$ & $\mathbf{S e q ~ S S}^{\mathbf{b}}$ & $\mathbf{A d j ~ S S}^{\mathbf{c}}$ & $\mathbf{A d j}_{\mathbf{M S}}^{\mathbf{d}}$ & $\mathbf{F}$ & $\mathbf{P}^{\mathbf{e}}$ & $\mathbf{\% P}^{\mathbf{P}}$ \\
\hline Load & 2 & 0.2480 & 0.2480 & 0.12401 & 11.34 & 0.001 & 9.81 \\
\hline Speed & 2 & 1.1817 & 1.1817 & 0.59085 & 54.02 & 0.000 & 46.777 \\
\hline Distance & 2 & 0.8778 & 0.8778 & 0.43888 & 40.13 & 0.000 & 34.746 \\
\hline Residual Error & 20 & 0.2187 & 0.2187 & 0.01094 & & & 8.667 \\
\hline Total & 26 & 2.5262 & & & & & 100
\end{tabular}




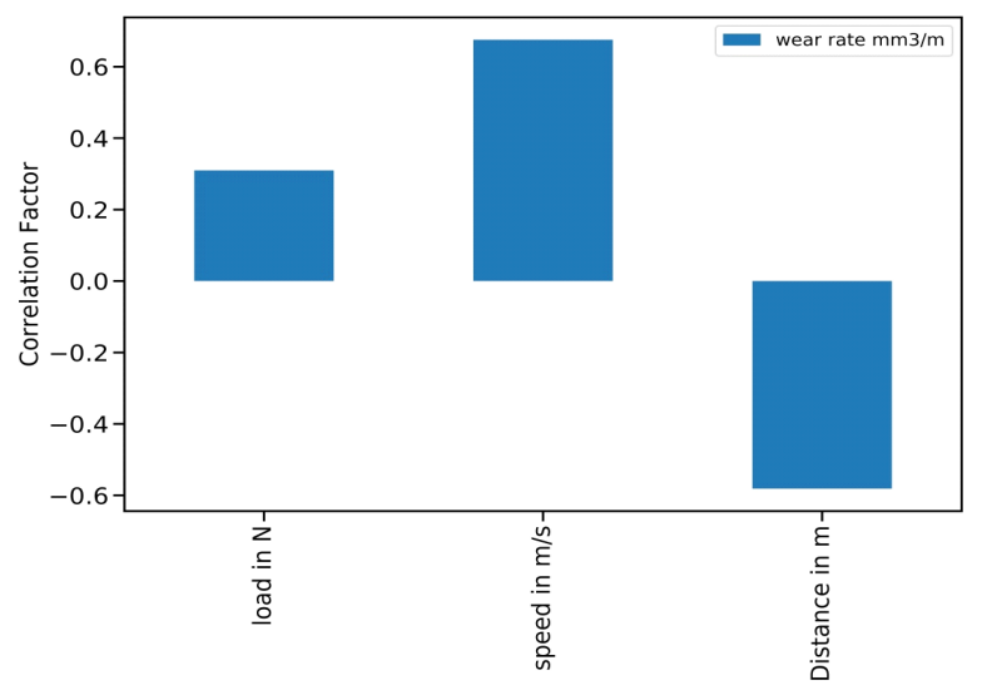

Figure 6. Correlation plot among the process parameters concerning wear rate.

\subsubsection{Regression analysis.}

A second-order polynomial regression equation for wear rate was extracted for potential determinants with an $\mathrm{R}-\mathrm{Sq}$ value of $97.5 \%$ to assess the wear rate in the given level of parameters through regression analysis. The mathematical model for wear rate is expressed in equation (1)

Wear rate $\left(\mathrm{mm}^{3} / \mathrm{m}\right)=0.00530+0.0523 \times \mathrm{L}+0.3398 \times \mathrm{S}-0.0016 \times \mathrm{D}-0.003 \times \mathrm{L}^{2}-0.0049 \times \mathrm{S}^{2}-$ $1.654 \times 10^{-5} \times \mathrm{D}^{2}+0.0445 \times \mathrm{L} \times \mathrm{S}-0.0004 \times \mathrm{L} \times \mathrm{D}+1.598 \times 10^{-06} \times \mathrm{S} \times \mathrm{D} \ldots \ldots$. Eq. (1)

The terms L, S, and D in the above equation represent the process parameters Load, Speed, and Distance. In the usual probability plot for wear rate, the residuals (errors) were normally distributed along the straight line, as shown in Figure 7.

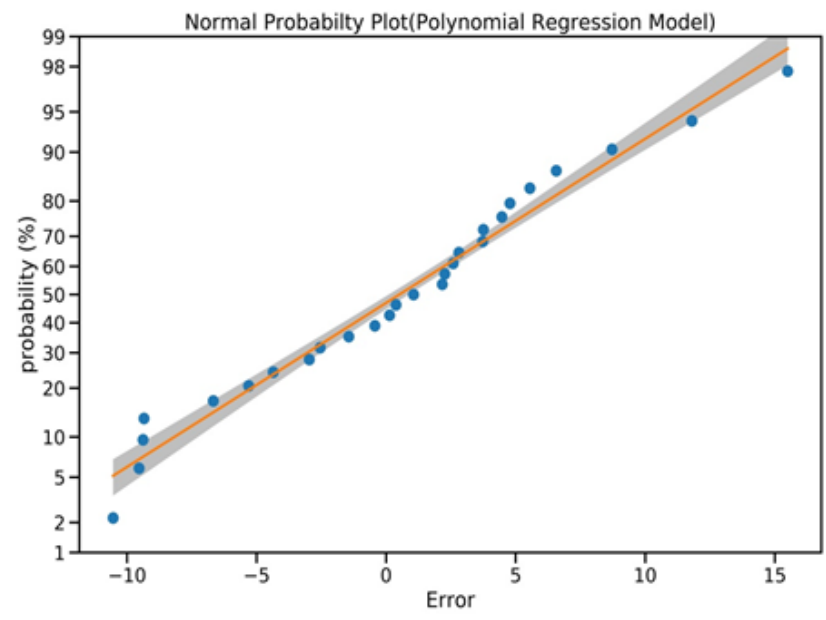

Figure 7. Normal probability plot for wear rate.

\subsection{Comparison between as-cast and heat-treated $\mathrm{Al}$ with $\mathrm{B}_{4} \mathrm{C}$ sample.}

From Table 3, the minimum wear $\left(0.419 \times 10^{-3} \mathrm{~mm}^{3} / \mathrm{m}\right)$ occurred at a load of $20 \mathrm{~N}$, speed of $1.25 \mathrm{~m} / \mathrm{s}$ and at $800 \mathrm{~m}$, and maximum wear $\left(1.679 \times 10^{-3} \mathrm{~mm}^{3} / \mathrm{m}\right)$ occurred at a load of $40 \mathrm{~N}$, speed of $3.76 \mathrm{~m} / \mathrm{s}$ and at $400 \mathrm{~m}$. These parameters were fixed to study the wear rate on samples not subjected to the age-hardening process. The results were recorded in Table 6 to compare the wear rate on age-hardened samples for the same aforesaid fixed parameters. The 
experimental results were plotted and shown in Figure 8 for comparison. It is evident that the wear rate for age-hardened samples was comparatively lower than that of cast samples for the same fixed parameters. The wear rate for age-hardened samples reduced approximately by $45 \%$ for a speed of $1.25 \mathrm{~m} / \mathrm{s}$ and $25 \%$ for a speed of $3.76 \mathrm{~m} / \mathrm{s}$. The improvements in wear resistance of aged samples were understood by studying worn-out samples. After conducting the wear test, the worn-out surfaces for both age-hardened and as-cast specimens were studied to evaluate the wear mechanism and compare the severity of wear using SEM. Figures 9 (a) and (c) show that the worn-out surface is mild, with light grooves, scratches, and debris visible. Due to the fine-grained microstructure and increased hardness, wear is not severe on specimens subjected to age-hardening. The formation of precipitates in age-hardened $\mathrm{Al} 2618+10 \% \mathrm{~B}_{4} \mathrm{C}$ offers more resistance to plastic deformation, thus improving wear resistance, higher strength, and hardness. However, in Figures 9 (b) and (d), the surface showing intense grooves, cracks, and the worn-out surface is more severe than as-cast specimens. The wear rate for the agehardened specimens was less compared to as-cast alloy (Fig. 8).

Even though the sliding distance was higher, the wear rate was less for age-hardened specimens (Figure 9a and 8c). As the sliding distance increased from 400 to $600 \mathrm{~m}$, there was a decrease in wear rate, and from 600 to $800 \mathrm{~m}$ distance, the wear rate was almost constant for a constant load of $20 \mathrm{~N}$, as shown in interaction plots Figure 5. This may be attributed to hard $\mathrm{B}_{4} \mathrm{C}$ reinforcements protruding at the interface, reducing the contact area between the sliding surfaces, leading to less wear rate. With the subsequent increase in sliding distance, these protruding reinforcements became blunt, and the overall contact surface area reduced, resulting in a constant or reduced wear rate. A similar study was carried out on Al-Si/illuminate reinforced composites via a stir casting route to study the effect of sliding distance. A constant wear rate trend was observed for distances in the range $2000 \mathrm{~m}$ to $3000 \mathrm{~m}$ [24]. The formation of a mechanically mixed layer and the simultaneous removal of the same layer was the reason behind the constant/steady-state wear rate trend. The wear mechanism differed for samples not subjected to the age-hardening process (Figures $9 \mathrm{~b}$ and $8 \mathrm{~d}$ ). The wear mechanism is exacerbated at higher loads and speeds due to increased contact pressure at the interface between the specimen and the rotating disc (Figure 9b). An increase in frictional resistance led to the rise in temperature, softening of the matrix, plastic deformation, and hence, the wear rate was severe, as observed in Figure 9d. SEM micrograph clearly shows the severity of wear for as-cast specimens. The wear transition from abrasive to adhesive was predominant at lower and dominant at higher loads. Table 6 summarizes the findings of numerous Taguchi optimization studies.

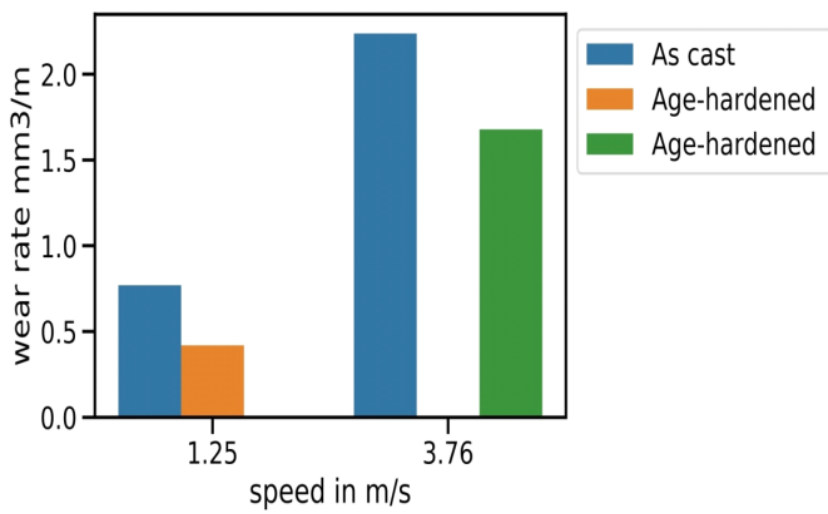

Figure 8. Wear rate comparisons between as-cast and Age-hardened samples. 

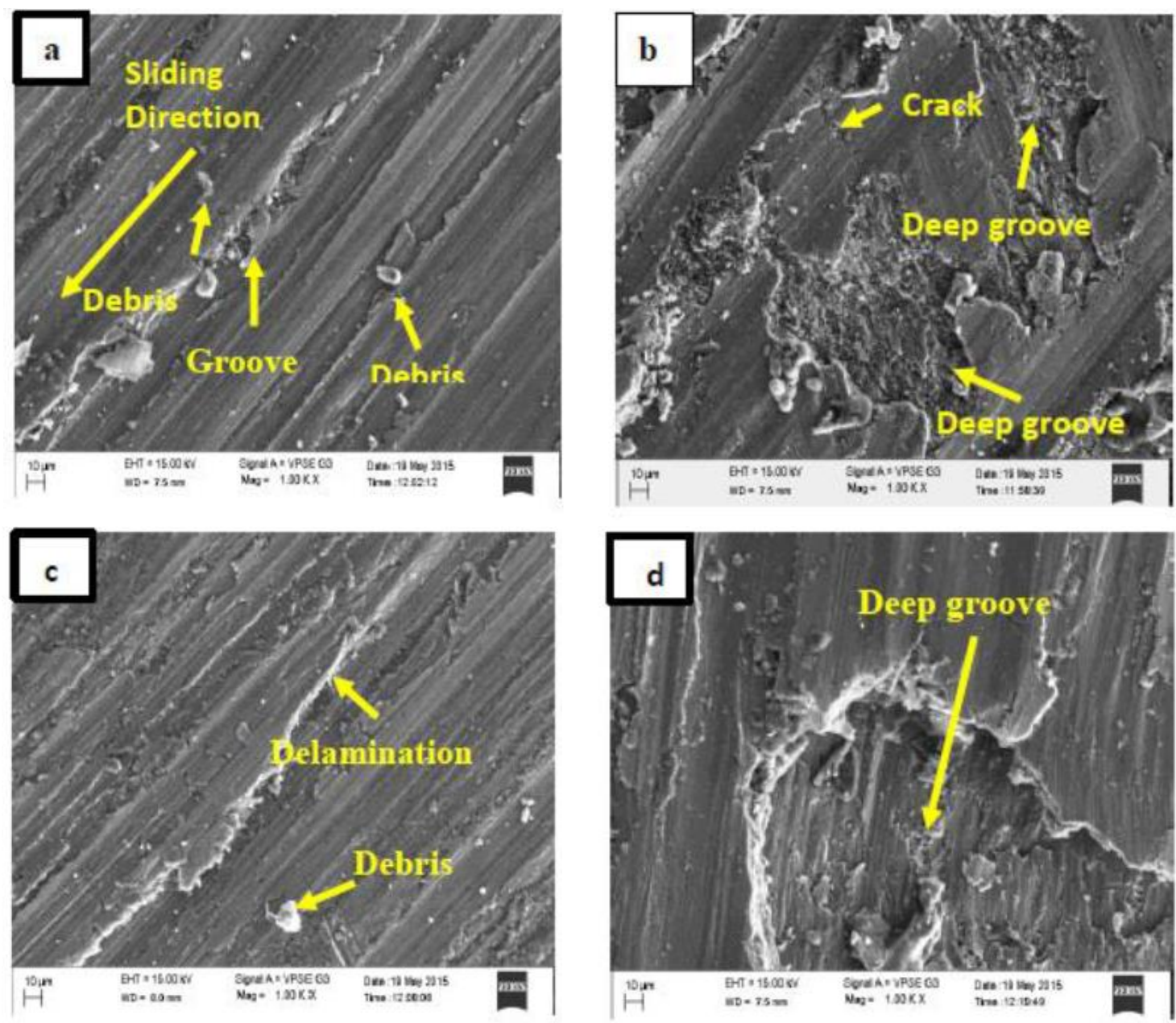

Figure 9. The SEM microstructure of the worn surfaces of $(A)$ and $(C)$ Worn out the surface of age-hardened specimens subjected to $\mathrm{L}=20 \mathrm{~N} ; \mathrm{S}=1.25 \mathrm{~m} / \mathrm{s}$ and $\mathrm{D}=800 \mathrm{~m}$, (B) \& (D) Worn out the surface of as-cast specimens subjected to $\mathrm{L}=40 \mathrm{~N} ; \mathrm{S}=3.76 \mathrm{~m} / \mathrm{s}$ and $\mathrm{D}=400 \mathrm{~m}$.

Table 6. Studies related to the Taguchi method for process optimization [25-37].

\begin{tabular}{l|l|l|l} 
Author & Year & Method & Material \\
\hline A. Saravanakumar et al. [25] & 2020 & Taguchi's L27 standard orthogonal array & AA2219-Gr Matrix Composite \\
\hline T. Satish et al. [26] & 2020 & Taguchi's L27 standard orthogonal array & $\begin{array}{l}\text { Al alloy 7050 reinforced with } \\
\text { SiC }\end{array}$ \\
\hline S. Arunkumar et al. [27] & 2020 & Taguchi's L8 standard orthogonal array & $\begin{array}{l}\text { Al7075 hybrid metal matrix } \\
\text { composite }\end{array}$ \\
\hline Eshan Agrawal et al. [28] & 2020 & Taguchi's L16 standard orthogonal array & Al-TiC composite \\
\hline Sadanand Sarapure et al. [29] & 2020 & Taguchi's L27 standard orthogonal array & $\begin{array}{l}\text { SiC-Reinforced Al 6061/SiC } \\
\text { Metal Matrix Composite }\end{array}$ \\
\hline Imran Mohsin et al. [30] & 2020 & Taguchi's L18 standard orthogonal array & 316L Stainless steel \\
\hline Tan Koon Tatt et al. [31] & 2020 & Taguchi's L81 orthogonal array & 316L Stainless steel powder \\
\hline Bo Yang et al. [32] & 2020 & Taguchi's L9 standard orthogonal array & Inconel 625 \\
\hline Sunil Kumar et al. [33] & 2020 & Taguchi's L9 standard orthogonal array & Ti alloy \\
\hline Zhe Wang et al. [34] & 2021 & Taguchi's L9 standard orthogonal array & TC17 alloy \\
\hline Ramiro J Sanchez et al. [35] & 2021 & $\begin{array}{l}\text { Taguchi's L9 standard orthogonal array- } \\
\text { based fuzzy logic approach }\end{array}$ & Canola Seed \\
\hline $\begin{array}{l}\text { Mohammad Nishat Akhtar } \text { et } \\
\text { al. [36] }\end{array}$ & 2021 & Taguchi's L27 standard orthogonal array & Aluminum 7075 Alloy \\
\hline Emine Sap et al. [37] & 2021 & Taguchi's L8 standard orthogonal array & Cu/Mo-SiCP Composite
\end{tabular}

\section{Conclusions}

The stir casting route successfully fabricated the composite. Design of experiments conducted using L27 orthogonal array on the age-hardened metal matrix composites (MMCs) 
to understand some wear mechanism fundamentals. ANOVA results confirmed that sliding speed and distance are the most significant parameters for wear studies on Al2618-10 wt. \% $\mathrm{B}_{4} \mathrm{C}$ MMC. Both sliding speed and applied load positively correlate with the wear rate, and sliding distance is negatively correlated. For better responses, load and speed must be kept at a low level but the distance at a high level. The wear test results indicated that the wear rate increases with increasing load and sliding speed, but the wear rate decreases with increasing sliding distance. Age hardening improved the hardness and wear resistance of the composite. SEM images show the proper distribution of reinforcement particles, and the nature of wear in age-hardened composite was mild. The reinforcement in the matrix improved the wear resistance of the composite. These observations corroborate that age-hardening enhances the wear resistance, strength, and other tribological properties owing to less material removal rate and prolonged service life of the components.

\section{Funding}

This research did not receive any specific grant from funding agencies in the public, commercial, or not-for-profit sectors.

\section{Acknowledgments}

This research has no acknowledgment.

\section{Conflicts of Interest}

The authors declare that they have no known competing financial interests or personal relationships that could have influenced the work reported in this paper.

\section{References}

1. Prasad, N.; Wanhill, R. Aerospace Materials and Material Technologies. Aerospace Material Technologies. 2017, 2, http://dx.doi.org/10.1007/978-981-10-2143-5.

2. Pugalethi, P.; Jayaraman, M.; Natarajan, A. Evaluation of Mechanical Properties of Aluminium Alloy 7075 Reinforced with $\mathrm{SiC}$ and Al2O3 Hybrid Metal Matrix Composites. Applied Mechanics and Materials 2015, 766-767, 246-251, https://doi.org/10.4028/www.scientific.net/AMM.766-767.246.

3. Eacherath, S.; Murugesan, S. Synthesis and characterization of magnesium-based hybrid composites-A review. International Journal of Materials Research 2018, 109, 661-672, https://doi.org/10.3139/146.111645.

4. Alam, T.; Ansari, A. Review On Aluminium And Its Alloys For Automotive Applications. International Journal of Advanced Technology In Engineering and Science 2017, 5, 278-294.

5. FeyzullahoĞLu, E.; ErtÜRk, A.T.; GÜVen, E.A. Influence of forging and heat treatment on wear properties of Al-Si and Al-Pb bearing alloys in oil lubricated conditions. Transactions of Nonferrous Metals Society of China 2013, 23, 3575-3583, http://doi.org/10.1016/s1003-6326(13)62903-9.

6. Sharma, A.K.; Bhandari, R.; Aherwar, A.; Rimašauskienė, R. Matrix materials used in composites: A comprehensive study. Materials Today: Proceedings 2020, 21, 1559-1562, https://doi.org/10.1016/j.matpr.2019.11.086.

7. Suresha, S.; Sridhara, B.K. Effect of silicon carbide particulates on wear resistance of graphitic aluminium matrix composites. Materials \& Design 2010, 31, 4470-4477, http://dx.doi.org/10.1016/j.matdes.2010.04.053.

8. Basavarajappa, S.; Chandramohan, G.; Mahadevan, A.; Thangavelu, M.; Subramanian, R.; Gopalakrishnan, P. Influence of sliding speed on the dry sliding wear behaviour and the subsurface deformation on hybrid metal matrix composite. Wear 2007, 262, 1007-1012, http://dx.doi.org/10.1016/j.wear.2006.10.016.

9. Gopalakrishnan, S.; Murugan, N. Production and wear characterisation of AA 6061 matrix titanium carbide particulate reinforced composite by enhanced stir casting method. Composites Part B: Engineering 2012, 43, 302-308, https://doi.org/10.1016/j.compositesb.2011.08.049. 
10. Veeresh Kumar, G.B.; Rao, C.S.P.; Selvaraj, N. Studies on mechanical and dry sliding wear of Al6061-SiC composites. Composites Part B: Engineering 2012, 43, 1185-1191, https://doi.org/10.1016/j.compositesb.2011.08.046.

11. Shankar, G.; Kini, A.; Shettar, M.; Hiremath, P. Aging kinetics and microstructural features of Al6061-SiC+ B4C stir cast hybrid composites. International Journal of Automotive and Mechanical Engineering 2019, 16, 7211-7224, https://doi.org/10.15282/ijame.16.4.2019.04.0538.

12. Banerjee, S.; Robi, P.S.; Srinivasan, A.; Praveen Kumar, L. High temperature deformation behavior of Al$\mathrm{Cu}-\mathrm{Mg}$ alloys micro-alloyed with Sn. Materials Science and Engineering: A 2010, 527, 2498-2503, http://dx.doi.org/10.1016/j.msea.2010.01.052.

13. Benal, M.M.; Shivanand, H.K. Effects of reinforcements content and ageing durations on wear characteristics of $\mathrm{Al}$ (6061) based hybrid composites. Wear 2007, 262, 759-763, http://dx.doi.org/10.1016\%2Fj.wear.2006.08.022.

14. Mehta, V.R.; Sutaria, M.P. Investigation on the Effect of Stirring Process Parameters on the Dispersion of SiC Particles Inside Melting Crucible. Metals and Materials International 2021, 27, 2989-3002, https://doi.org/10.1007/s12540-020-00612-0.

15. Özbek, İ. A study on the re-solution heat treatment of AA 2618 aluminum alloy. Materials Characterization 2007, 58, 312-317, http://dx.doi.org/10.1016/j.matchar.2006.07.002.

16. Kun, M.; Tingting, L.; Ya, L.; Xuping, S.; Jianhua, W. Study on Strengthening and Toughening Mechanisms of Aluminum Alloy 2618-Ti at Elevated Temperature. High Temperature Materials and Processes 2018, 37 , 9-15, https://doi.org/10.1515/htmp-2015-0226.

17. Sharath, B.N.; Madhu, K.S.; Venkatesh, C.V. Experimental Study on Dry Sliding Wear Behaviour of AlB4C-Gr Metal Matrix Composite at Different Temperatures. Applied Mechanics and Materials 2019, 895, 96-101, https://doi.org/10.4028/www.scientific.net/AMM.895.96.

18. Rao, R.N.; Das, S. Effect of SiC content and sliding speed on the wear behaviour of aluminium matrix composites. Materials \& Design 2011, 32, 1066-1071, https://doi.org/10.1016/j.matdes.2010.06.047.

19. Al-Samarai, R.A.; Haftirman, A.K.; Al-Douri, Y. Effect of Load and Sliding Speed on Wear and Friction of Aluminum- Silicon Casting Alloy. International Journal of Scientific and Research Publications 2012, 2, 14.

20. Al-Qutub, A.M.; Allam, I.M.; Abdul Samad, M.A. Wear and friction of Al-Al2O3 composites at various sliding speeds. Journal of Materials Science 2008, 43, 5797-5803, https://doi.org/10.1007/s10853-008-28678 .

21. Sahin, Y.; Murphy, S. The effect of fibre orientation of the dry sliding wear of borsic-reinforced 2014 aluminium alloy. Journal of Materials Science 1996, 31, 5399-5407, https://doi.org/10.1007/BF01159309.

22. Soy, U.; Ficici, F.; Demir, A. Evaluation of the Taguchi method for wear behavior of Al/SiC/B4C composites. Journal of Composite Materials 2011, 46, 851-859, https://doi.org/10.1177\%2F0021998311410510.

23. Straffelini, G.; Pellizzari, M.; Molinari, A. Influence of load and temperature on the dry sliding behaviour of Al-based metal-matrix-composites against friction material. Wear 2004, 256, 754-763, http://dx.doi.org/10.1016/S0043-1648(03)00529-5.

24. Sharma, S.; Nanda, T.; Pandey, O.P. Effect of particle size on dry sliding wear behaviour of sillimanite reinforced aluminium matrix composites. Ceramics International 2018, 44, 104-114, https://doi.org/10.1016/j.ceramint.2017.09.132.

25. Saravanakumar, A.; Rajeshkumar, L.; Balaji, D.; Jithin Karunan, M.P. Prediction of Wear Characteristics of AA2219-Gr Matrix Composites Using GRNN and Taguchi-Based Approach. Arabian Journal for Science and Engineering 2020, 45, 9549-9557, https://doi.org/10.1007/s13369-020-04817-8.

26. Sathish, T.; Karthick, S. Wear behaviour analysis on aluminium alloy 7050 with reinforced $\mathrm{SiC}$ through taguchi approach. Journal of Materials Research and Technology 2020, 9, 3481-3487, https://doi.org/10.1016/j.jmrt.2020.01.085.

27. Arunkumar, S.; Ashokkumar, R.; Sundaram, M.S.; SukethKanna, K.M.; Vigneshwara, S. Optimization of wear behaviour of A17075 hybrid metal matrix composites using Taguchi approach. Materials Today: Proceedings 2020, 33, 570-577, https://doi.org/10.1016/j.matpr.2020.05.453.

28. Agrawal, E.; Tungikar, V. Study on tribological properties of Al-TiC composites by Taguchi method. Materials Today: Proceedings 2020, 26, 2242-2247, https://doi.org/10.1016/j.matpr.2020.02.486.

29. Sarapure, S.; Shivakumar, B.P.; Hanamantraygouda, M.B. Investigation of Corrosion Behavior of SiCReinforced Al 6061/SiC Metal Matrix Composites Using Taguchi Technique. Journal of Bio- and TriboCorrosion 2020, 6, 1-8, https://doi.org/10.1007/s40735-020-0328-3.

30. Mohsin, I.; He, K.; Li, Z.; Zhang, F.; Du, R. Optimization of the Polishing Efficiency and Torque by Using Taguchi Method and ANOVA in Robotic Polishing. Applied Sciences 2020, 10, 1-15, http://dx.doi.org/10.3390/app10030824.

31. Tatt, T.K.; Hassan, C.; Bakar, A. Parametric Optimization of Metal Injection Moulding Process Using Taguchi Method. International Journal of Integrated Engineering 2020, 12, 210-219.

32. Yang, B.; Lai, Y.; Yue, X.; Wang, D.; Zhao, Y. Parametric Optimization of Laser Additive Manufacturing of Inconel 625 Using Taguchi Method and Grey Relational Analysis. Scanning 2020, 2020, 1-10, https://doi.org/10.1155/2020/9176509. 
33. Kumar, S.; Yadav, R.N.; Kumar, R. Modelling and optimisation of duplex turning of titanium alloy (grade 5) using Taguchi methodology-response surface methodology. International Journal of Industrial and Systems Engineering 2020, 35, 463-481, https://dx.doi.org/10.1504/IJISE.2020.108549.

34. Wang, Z.; Li, L. Optimization of process parameters for surface roughness and tool wear in milling TC17 alloy using Taguchi with grey relational analysis. Advances in Mechanical Engineering 2021, 13, 1-8, https://doi.org/10.1177/1687814021996530.

35. Sánchez, R.J.; Blas, M.J.; Fernández, M.B.; Nolasco, S.M. Applying a Taguchi-based fuzzy logic approach to optimize hydrothermal pretreatment of canola seeds using multi-response performance index. OCL 2021, 28, 1-8, https://doi.org/10.1051/ocl/2020076.

36. Akhtar, M.N.; Sathish, T.; Mohanavel, V.; Afzal, A.; Arul, K.; Ravichandran, M.; Rahim, I.A.; Alhady, S.S.N.; Bakar, E.A.; Saleh, B. Optimization of Process Parameters in CNC Turning of Aluminum 7075 Alloy Using L27 Array-Based Taguchi Method. Materials 2021, 14, 1-26, https://doi.org/10.3390/ma14164470.

37. Şap, E.; Usca, Ü.A.; Gupta, M.K.; Kuntoğlu, M.; Sarıkaya, M.; Pimenov, D.Y.; Mia, M. Parametric Optimization for Improving the Machining Process of $\mathrm{Cu} / \mathrm{Mo}-\mathrm{SiCP}$ Composites Produced by Powder Metallurgy. Materials 2021, 14, 1-20, https://doi.org/10.3390/ma14081921. 